\title{
Anti-Migration and Anti-Invasion Effects of Curcumin via Suppression of Fascin Expression in Glioblastoma Cells
}

\author{
Ki-Su Park*, Sang-Youl Yoon*, Seong-Hyun Park, Jeong-Hyun Hwang \\ Department of Neurosurgery, School of Medicine, Kyungpook National University, Daegu, Korea
}

\author{
Received October 5, 2018 \\ Revised January 25, 2019 \\ Accepted February 22, 2019 \\ Correspondence \\ Jeong-Hyun Hwang \\ Department of Neurosurgery, \\ Kyungpook National University Hospital, \\ 130 Dongdeok-ro, Jung-gu, Daegu \\ 41944, Korea \\ Tel: +82-53-200-5652 \\ Fax: +82-53-423-0504 \\ E-mail: jhwang@knu.ac.kr \\ *These authors contributed equally to \\ this work.
}

\begin{abstract}
Background The natural compound curcumin was known to inhibit migration and invasion of glioblastoma (GBM) cells. Fascin, a kind of actin-binding proteins, is correlated with migration and invasion of GBM cells. The purpose of this study was to investigate anti-migration and anti-invasion effects of curcumin via suppression of fascin expression in GBM cells.
\end{abstract}

Methods U87 cell line was used as an experimental model of GBM. Fascin was quantified by Western blot analysis. And, the signal transducer and activator of transcription 3 (STAT3), known to play an important role in migration and invasion of tumor cells, were analyzed by sandwich-ELISA. Migration and invasion capacities were assessed by attachment, migration and invasion assays. Cellular morphology was demonstrated by immunofluorescence.

Results At various concentrations of curcumin and exposure times, fascin expression decreased. After temporarily exposure to $10 \mu \mathrm{M} / \mathrm{L}$ curcumin during 6 hours as less invasive concentration and time, fascin expression temporarily decreased at 12 hours (18.4\%, $p=0.024)$, and since then recovered. And, the change of phosphrylated STAT3 level also reflected the temporarily decreased pattern of fascin expression at 12 hours $(19.7 \%, p=0.010)$. Attachment, migration, and invasion capacities consistently decreased at 6,12 , and 24 hours. And, immunofluorescence showed the change of shape and the reduction of filopodia formation in cells.

Conclusion Curcumin is likely to suppress the fascin expression in GBM cells, and this might be a possible mechanism for anti-migration and anti-invasion effects of Curcumin via inhibition of STAT3 phosphorylation.

Key Words Glioblastoma; Fascin; Curcumin; STAT3 transcription factor.

\section{INTRODUCTION}

Malignant glioma cells are extremely invasive. They easily migrate and invade into surrounding brain parenchyma, which leads naturally to tumor progression and subsequent treatment failure. In order to migrate and invade into the surrounding environment, glioma cells modify their shape and rigidity. Modification of shape and rigidity involves rearranging the actin cytoskeleton, which in turn involves multiple actin-binding proteins [1-3].

This is an Open Access article distributed under the terms of the Creative Commons Attribution Non-Commercial License (https://creativecommons.org/licenses/by-nc/4.0) which permits unrestricted non-commercial use, distribution, and reproduction in any medium, provided the original work is properly cited.

Copyright $\odot 2019$ The Korean Brain Tumor Society, The Korean Society for NeuroOncology, and The Korean Society for Pediatric Neuro-Oncology
Fascin, one of actin-binding proteins, structurally reinforces a cytoplasmic microfilament bundle and is an important component in cell architecture and cellular movement. A series of studies have demonstrated that fascin expression increases the proliferation and invasion of human carcinomas [4]. Additionally, fascin promotes cancer cell migration and invasion in a signal transducer and activator of transcription 3 (STAT3)-dependent manner [5]. Recent literature has suggested that fascin is highly expressed in malignant glioma cells, especially glioblastoma (GBM), and may be related with the migration and invasion of glioma cells [1,3,6-8].

Curcumin (diferuloylmethane) is a curcuminoid of turmeric, an Indian spice derived from the plant Curcuma longa Linn [9]. As a main ingredient in curries, which is a component of the diet for many people, curcumin is standardly considered 
safe in humans $[10,11]$. Further, curcumin has been shown to have antioxidant, anti-infective and anticancer effects; and these effect are still being investigated [12]. Especially, recent numerous groups have been studying the potential anti-GBM properties of curcumin [9-11,13-17].

Although there have been many reports about the antiGBM properties of curcumin, the anti-migration and anti-invasion effects of curcumin related to fascin expression in GBM cells have yet to be reported. Thus, the purpose of this study was to analyze the effects of curcumin on fascin expression in GBM cells, and to suggest a possible mechanism that the suppression of fascin expression by curcumin may cause anti-migration and anti-invasion effects.

\section{MATERIALS AND METHODS}

\section{Cell culture}

Human GBM cell line known as U87 were purchased from Sigma-Aldrich (St. Louis, MO, USA). A human primary GBM cell line previously known as U87 was used to derive cell lines. Cells were cultivated in a high glucose ( $4.5 \mathrm{~g} / \mathrm{L})$ Dulbecco's Modified Eagle Medium that had 10\% heat inactivated fetal calf serum, $100 \mathrm{mg} / \mathrm{mL}$ streptomycin, and $100 \mathrm{U} / \mathrm{mL}$ penicillin. Cells were grown at $37^{\circ} \mathrm{C}$ in an atmosphere that was humidified and composed of $95 \%$ air and $5 \% \mathrm{CO}_{2}[16]$.

\section{Cell viability assay}

The 3-(4,5-dimethylthiazol-2-yl)-5-(3-carboxymethoxyphenyl)- 2-(4-sulfophenyl)-2H-tetrazolium, inner salt (MTS) assay kit (CellTiter 96 Aqueous One Solution, Promega, Modison, WI, USA) was used to measure cell viability. Immediately before the experiments, the curcumin was stored at $-20^{\circ} \mathrm{C}$ and then dissolved in dimethyl sulfoxide and diluted to the target concentration. The U87 cells were seeded in a 96-well plate at a density of 5,000 cells/well and were then allowed to adhere overnight. Subsequently, the U87 cells were incubated in fetal bovine serum (FBS)-free media that contained different concentrations of curcumin $(0,10,20,30,40$, and $50 \mu \mathrm{M} /$ L). Then, an MTS reagent was added to each well; and the 96well plates were incubated at $37^{\circ} \mathrm{C}$ over various durations (6, 24,48 , and 72 hours) in a humidified incubator maintained with $5 \% \mathrm{CO}_{2}$. The optical density was measured to be $490 \mathrm{~nm}$ with a microplate spectrophotometer.

\section{Western blot}

Western blot analysis was used to quantify fascin expression. U87 cells were incubated for 6 hours in FBS-free media that contained 0 and $10 \mu \mathrm{M} / \mathrm{L}$ curcumin, and then were washed with phosphate-buffered saline (PBS). Cells were collected after 6,12 , and 24 hours, and then were lysed with a lysis buffer solution [25 mM Tris-Cl pH 7.6, $150 \mathrm{mM} \mathrm{NaCl}, 1 \%$ NP-40, $1 \%$ sodium deoxycholate, $0.1 \%$ sodium dodecyl sulfate (SDS), and protease inhibitor cocktail, Roche, Mannheim, Germany]. Cell lysate was centrifuged at 13,000 revolutions per minute for 30 minutes at $4^{\circ} \mathrm{C}$, and then the supernatant were separated and the proteins were quantified with a bicinchoninic acid protein assay (Sigma, St. Louis, MO, USA). Protein samples were separated with a $10 \%$ SDS-polyacrylamide electrophoresis gel and then were moved to membranes (Millipore, Bedford, MA, USA). The membranes were blocked for 1 hour at room temperature with a 5\% non-fat dry milk in a Tris-buffered saline that contained $0.1 \%$ Tween-20. After incubation at $4^{\circ} \mathrm{C}$ overnight with a 1:1,000 dilution of mouse monoclonal anti-fascin (Santa Cruz Biotechnology, Santa Cruz, CA, USA), followed by a peroxidase-conjugated secondary antibody at room temperature for 1 hour, signals were then detected using an enhanced chemiluminescence system (Amersham Biosciences, Buckinghamshire, UK). An ImageJ computer-assisted image analyzer was used to calculated band densities (version 1.146r, National Institutes of Health, Bethesda, MD, USA).

\section{Sandwich ELISA}

To determine the effect of curcumin on the upstream pathway of fascin expression, sandwich-ELISA was used to analyze the STAT3, a transcription factor connected to a master regulator of human gliomas central to maintaining a tumor's initiating capacity and ability to invade brain parenchyma [18]. After U87 cells were incubated in FBS-free media containing $10 \mu \mathrm{M} / \mathrm{L}$ curcumin for 6 hours and cleaned with PBS, the cells were seeded on a $100 \mathrm{~mm}$ plate at a density of $8 \times 10^{5}$ cells/well and were permitted to adhere overnight. The cells were collected after 6, 12, and 24 hours and lysed with an ice-cold lysis buffer solution ( $150 \mathrm{mM} \mathrm{NaCl}, 25 \mathrm{mM}$ Tris-Cl pH 7.6, 1\% NP$40,0.1 \%$ SDS, $1 \%$ sodium deoxycholate, and protease inhibitor cocktail, Roche, Mannheim, Germany). The concentrations of total or phosphorylated STAT3 in the samples were determined using sandwich-ELISA kits [Human STAT3 ELISA Kit; LifeSpan Biosciences, Inc., Seattle, WA, USA and PathScan Phospho-Stat3 (Tyr705) ELISA kit; Cell Signaling Technology Inc., Danvers, MA, USA]. After coating of the microplate wells, $100 \mu \mathrm{L}$ of the lysates were added to a microplate well, and then they were incubated for 2 hours at $37^{\circ} \mathrm{C}$ before the well was cleaned, and then a detection antibody was added for 1 hour. Subsequently, $100 \mu \mathrm{L}$ of a secondary polyclonal antibody conjugated to horseradish peroxidase was added into each well. The plate was then incubated at room temperature for 30 minutes. Later, a $200 \mu \mathrm{L}$ of substrate solution (tetramethylbenzidine) was incubated in each well for 10 minutes at $37^{\circ} \mathrm{C}$. The reaction was then terminated through the addition of $100 \mu \mathrm{L}$ of stop solution ( $2 \mathrm{~N}$ sulfuric acid). The color in 
the wells changed from blue to yellow. A microplate reader was used to measure the optical density of each well (VersaMax, Molecular Device Inc., Sunnyvale, CA, USA) set to $450 \mathrm{~nm}$.

\section{Attachment assay}

Ninety-six well plates were incubated with laminin at 10 $\mu \mathrm{g} / \mathrm{mL}$ overnight at $4^{\circ} \mathrm{C}$. Unbound sites were restricted with $0.1 \%$ bovine serum albumin (BSA) for 1 hour. U87 cells, which were temporarily treated with $10 \mu \mathrm{M} / \mathrm{L}$ and $20 \mu \mathrm{M} / \mathrm{L}$ curcumin for 6 hours, were seeded at a density of $5 \times 10^{4}$ cells/well on BSA-coated or laminin plates. The cells were allowed to adhere in a humidified incubator supplied with $5 \% \mathrm{CO}_{2}$ at $37^{\circ} \mathrm{C}$ for 6 , 12 , and 24 hours. After cleaning with PBS, the cells that remained were fixed for 10 minutes with $4 \%$ paraformaldehyde, and then were stained with $5 \%$ crystal violet for 20 minutes at room temperature. Cells were solubilized with $1 \%$ SDS; then a microplate reader (VersaMax) set to $595 \mathrm{~nm}$ was used to measure the absorbance of each well.

\section{Migration assay}

U87 cells were first plated in six well dishes at a density of $3 \times 10^{5}$ cells/well, and then were allowed to attach and reach a subconfluency of $80 \%$. Thereafter, the cells were incubated using a starvation medium that contained $10 \mu \mathrm{M} / \mathrm{L}$ and 20 $\mu \mathrm{M} / \mathrm{L}$ curcumin for 6 hours. A yellow pipet tip was used to perform a scratch through a cell monolayer in FBS-free media. Cells were photographed using an Axioplan-2 epifluorescence microscope (Carl Zeiss Vision GmbH, Munchen, Germany) after 6, 12, and 24 hours. A computer monitor was used to view the images using a Zeiss Plan-Apochromat $40 \times$ objective (Carl Zeiss Vision GmbH, Munchen, Germany). An ImageJ computer-assisted image analyzer was used to count the area of the scratch.

\section{Invasion assay}

A Matrigel coated modified Boyden chamber Biocoat $^{\mathrm{TM}}$ Matrigel ${ }^{\mathrm{TM}}$ Invasion Chamber; Becton Dickinson GmbH, Heidelberg, Germany) was used to evaluate cell invasion. Approximately $2.5 \times 10^{4}$ control and U87 cells treated with $10 \mu \mathrm{M} / \mathrm{L}$ and $20 \mu \mathrm{M} / \mathrm{L}$ curcumin for 6 hours were seeded into an upper well of the chamber that contained a $500 \mu \mathrm{L}$ serum free culture medium. A $500 \mu \mathrm{L}$ culture medium with $10 \%$ FBS was then introduced to the bottom of the well. After 6, 12, and 24 hours, non-invading cells in the top chamber were cautiously removed with a cotton swab and cells on the bottom of the chamber were fixed with $4 \%$ paraformaldehyde for $15 \mathrm{~min}$ utes at room temperature, and then were stained at room temperature for 10 minutes with $0.5 \%$ crystal violet. Subsequent to the crystal violet being rinsed with distilled water, the cells were photographed with an Axioplan-2 epifluores- cence microscope (Carl Zeiss Meditec Incorporation, Jena, Germany). The images were displayed on a computer monitor that used a Zeiss Plan-Apochromat 100× objective (Carl Zeiss).

\section{Immunofluorescence}

To determine the morphological changes of GBM cells by curcumin, immunofluorescence was performed. After temporary exposure of 0 and $10 \mu \mathrm{M} / \mathrm{L}$ curcumin for 6 hours, U87 cells were cleaned with PBS three times. After 6 and 24 hours, the cells were fixed for 10 minutes with $4 \%$ paraformaldehyde and then were permeabilized for 5 minutes at room temperature with $0.5 \%$ Triton X-100 in PBS. Nonspecific binding was blocked for 1 hour at room temperature by $1 \%$ BSA in PBS. Subsequently, the cells were incubated for 1 hour with an anti-Fascin monoclonal antibody. After cleaning, the cells were then incubated at room temperature for 30 minutes with $\mathrm{Al}$ exa Fluor 488 (Molecular Probes, Eugene, OR, USA)-conjugated goat anti-mouse IgG secondary antibodies. A computer monitor using a Zeiss Plan-Apochromat $40 \times$ objective was used to view the images.

\section{Statistical analysis}

All statistical comparisons were computed using SPSS 21.0 (IBM Corp., Armonk, NY, USA). Data were expressed as mean \pm standard error of the mean. Repeated measure ANOVA was used to compare groups. Null hypotheses of no difference were rejected if $p$-values were less than 0.05 .

\section{RESULTS}

\section{Minimally lethal concentration of curcumin and exposure time by means of cell viability assays}

In terms of concentrations, U87 cells were treated with different concentrations of curcumin $(0,10,20,30,40$, and 50 $\mu \mathrm{M} / \mathrm{L}$ ) during same time (24 hours). MTS assays showed that cell viabilities decreased at all concentrations. However, cell viabilities at $10 \mu \mathrm{M} / \mathrm{L}$ and $20 \mu \mathrm{M} / \mathrm{L}$ curcumin showed minimal decreases compared to control group $(10 \mu \mathrm{M} / \mathrm{L}: 80.8 \%$ and $20 \mu \mathrm{M} / \mathrm{L}: 78.2 \%)$. At concentrations higher than $20 \mu \mathrm{M} / \mathrm{L}$, cell viabilities steeply declined (Fig. 1A).

In terms of exposure times, U87 cells were treated with 10 $\mu \mathrm{M} / \mathrm{L}$ and $20 \mu \mathrm{M} / \mathrm{L}$ curcumin over various times $(6,24,48$ and 72 hours). Although cell viabilities decreased over all times, the cell viabilities at $10 \mu \mathrm{M} / \mathrm{L}$ and $20 \mu \mathrm{M} / \mathrm{L}$ curcumin during 6 hours revealed minimal decreases compared to control group $(10 \mu \mathrm{M} / \mathrm{L}: 93.9 \%$ and $20 \mu \mathrm{M} / \mathrm{L}: 90.5 \%)$. After 6 hours, cell viabilities revealed consistent decreases below 80\% (Fig. 1B).

Consequently, according to the cell viability assays, $10 \mu \mathrm{M} / \mathrm{L}$ and $20 \mu \mathrm{M} / \mathrm{L}$ curcumin and 6 hours were chosen as the min- 

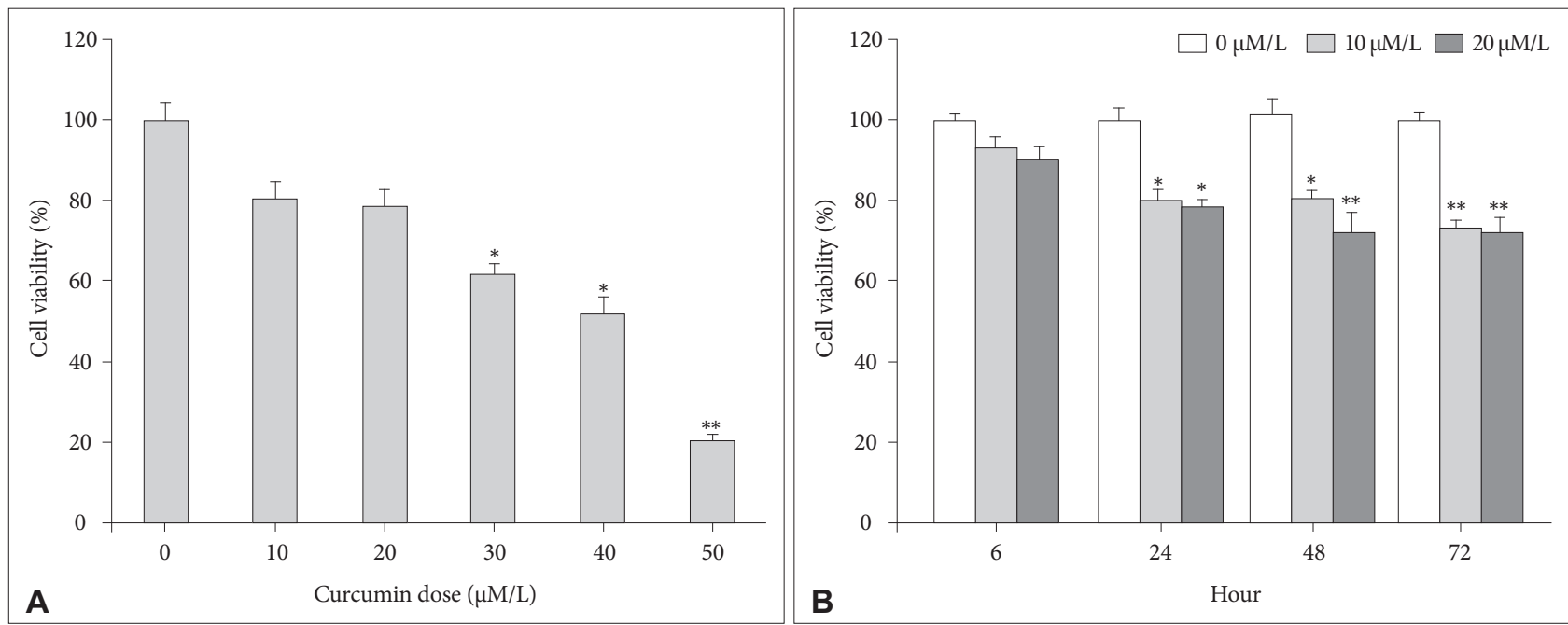

Fig. 1. MTS assay for cell viability. A: At $10 \mu \mathrm{M} / \mathrm{L}$ and $20 \mu \mathrm{M} / \mathrm{L}$ concentrations of curcumin, cell viabilities showed minimal decreases (10 $\mu \mathrm{M} / \mathrm{L}: 80.8 \%, 20 \mu \mathrm{M} / \mathrm{L}: 78.2 \%$ ). B: The cell viabilities at $10 \mu \mathrm{M} / \mathrm{L}$ and $20 \mu \mathrm{M} / \mathrm{L}$ curcumin for 6 hours were $93.9 \%$ and $90.5 \%$, respectively. ${ }^{*} p<0.05,{ }^{* *} p<0.001$ compared to the control group.

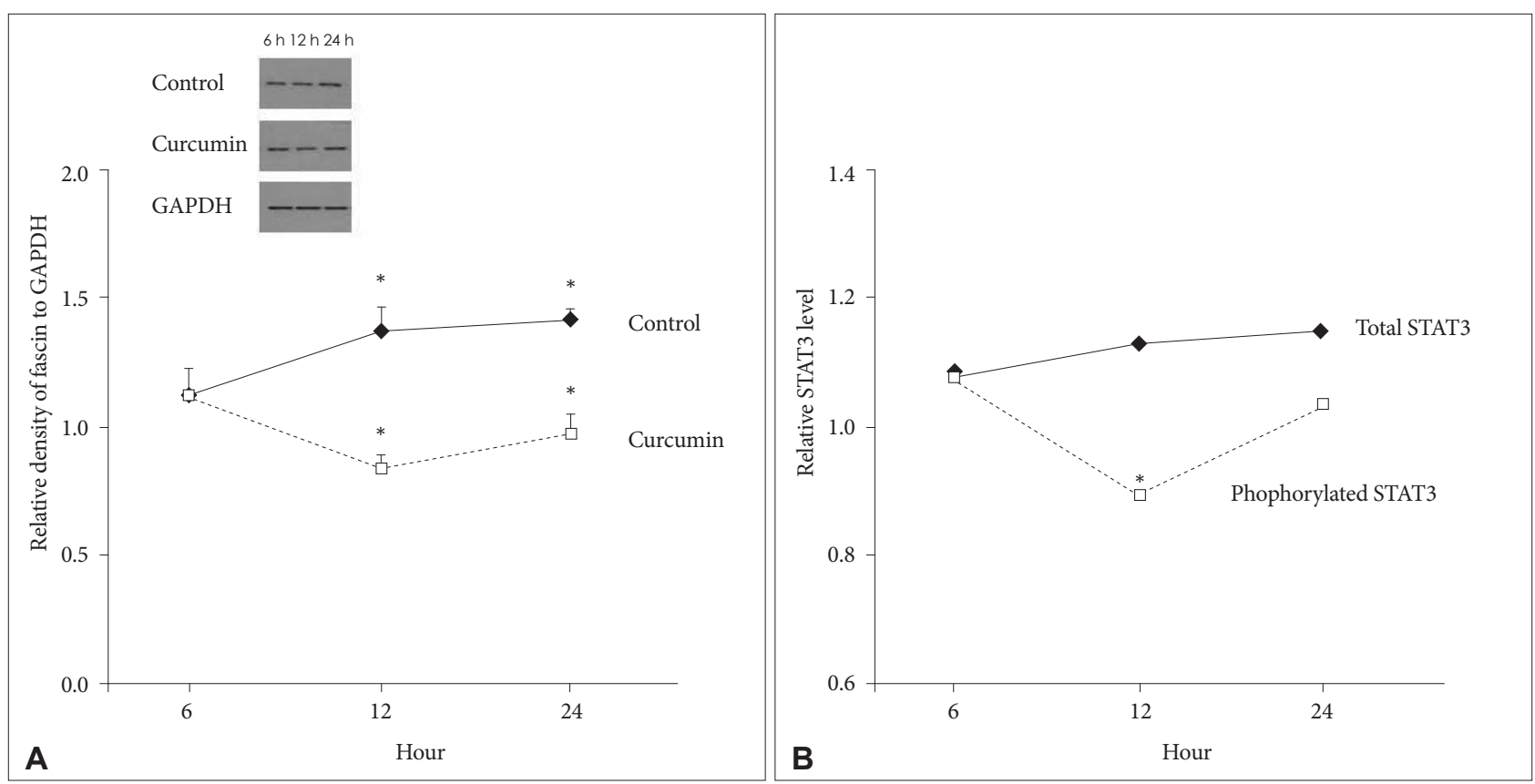

Fig. 2. Western blot analysis for quantification of fascin expression and sandwich ELISA for quantification of STAT3. A: Fascin expression temporarily decreased at 12 hours $(18.4 \%, p=0.024)$, but gradually recovered after 12 hours. B: The change of phosphorylated STAT3 level also reflected temporarily decreased patterns of fascin expression at 12 hours $(19.7 \%, p=0.010)$. Whereas concentrations of total STAT3 according to a time sequence were similar. Data were presented as the mean \pm SD. ${ }^{*} p<0.05$ compared to the control group. STAT3, signal transducer and activator of transcription 3.

imally lethal concentrations and exposure time to minimize cell death to an acceptable level.

\section{Curcumin suppresses fascin expression by STAT3 inhibition in GBM cells}

When GBM cells were temporarily treated with $10 \mu \mathrm{M} / \mathrm{L}$ curcumin during 6 hours as the lowest minimally lethal concentration and exposure time, fascin expression temporarily decreased after 12 hours (18.4\%, $p=0.024)$. Subsequently, it gradually recovered (Fig. 2A). Under the same circumstances, the change of phosphorylated STAT3 level also reflected temporarily decreased patterns of fascin expression at 12 hours $(19.7 \%, p=0.010)$. Whereas concentrations of total STAT3 according to a time sequence were similar (Fig. 2B).

Therefore, curcumin is likely to suppress fascin expression, even with a minimally lethal concentration and short exposure 


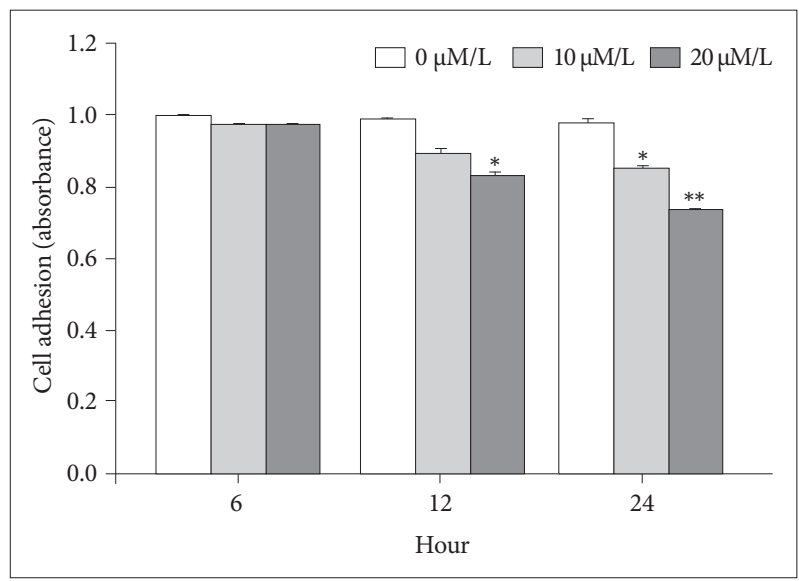

Fig. 3. Attachment assay. The attachment ability of glioblastoma cells showed a statistically significant decrease after 6 hours $(20$ $\mu \mathrm{M} / \mathrm{L}$ curcumin at 12 hours: $14.7 \%, p=0.001 ; 10$ and $20 \mu \mathrm{M} / \mathrm{L}$ curcumin at 24 hours: $12.6 \%$ and $24.4 \%, p=0.001$ and $p<0.001$ ). Data were presented as the mean \pm SD. ${ }^{*} p<0.05,{ }^{* *} p<0.001 \mathrm{com}-$ pared to the control group.

time. And, curcumin may suppress fascin expression in GBM cells via phosphorylated STAT3 downregulation.

\section{Suppression of fascin expression by curcumin may inhibit migration and invasion}

U87 cells were temporarily treated with $10 \mu \mathrm{M} / \mathrm{L}$ and $20 \mu \mathrm{M} / \mathrm{L}$ curcumin for 6 hours, and then the curcumin was washed out. Then attachment, migration and invasion assays were analyzed according to a time sequence, such as 6,12, and 24 hours.

The attachment ability of GBM cells showed a statistically significant decrease after 6 hours $(20 \mu \mathrm{M} / \mathrm{L}$ curcumin at 12 hours: $14.7 \%, p=0.001 ; 10 \mu \mathrm{M} / \mathrm{L}$ and $20 \mu \mathrm{M} / \mathrm{L}$ curcumin at 24 hours: $12.6 \%$ and $24.4 \%, p=0.001$ and $p<0.001$ ) (Fig. 3). The migration ability of GBM cells showed a statistically significant decline after 6 hours, and the closure percentage of GBM cells showed statistical differences when compared to control $(10 \mu \mathrm{M} / \mathrm{L}$ and $20 \mu \mathrm{M} / \mathrm{L}$ at 12 hours: $24.2 \%$ and $58.1 \%, p=0.031$ and $p<0.001$; at $10 \mu \mathrm{M} / \mathrm{L}$ and $20 \mu \mathrm{M} / \mathrm{L}$ at 24 hours: $25.0 \%$ and $54.3 \%, p=0.002$ and $p<0.001$ ) (Fig. 4). Additionally, the invasion ability of GBM cells showed a statistically significant decline after 6 hours $(10 \mu \mathrm{M} / \mathrm{L}$ and $20 \mu \mathrm{M} / \mathrm{L}$ at 12 hours: $28.8 \%$ and $43.2 \%, p=0.046$ and $p<0.001 ; 10 \mu \mathrm{M} / \mathrm{L}$ and $20 \mu \mathrm{M} / \mathrm{L}$ at 24 hours: $54.1 \%$ and $73.8 \%, p=0.001$ and $p<0.001$ ) (Fig. 5).

\section{Curcumin changes cell shape and reduce filopodia formation in GBM cells by suppression of fascin}

U87 cells were temporarily treated with $10 \mu \mathrm{M} / \mathrm{L}$ curcumin during 6 hours as the lowest minimally lethal concentration and exposure time, and then curcumin was washed out. Morphological changes of GBM cells were determined by immunofluorescence at 6 and 24 hours (Fig. 6).

Immunofluorescence showed change of cell shape from typical spindle form of uninfluenced cells to a more polygonal appearance, and a significant reduction in filopodia formation of GBM cells. And, even though filopodia remained, the length was shorter when compared to controls. Furthermore, there was no recovery of the morphological change in GBM cells according to a time sequence.

\section{DISCUSSION}

Fascin exists at high levels in the nervous system, especially in vascular endothelial cells, neurons, and glial cells [1923]. Fascin is a fundamental filopodial bundling protein, and it has a key role in the formation and protrusion of filopodia $[2,24,25]$. Fascin functioning is crucial to filopodial dynamics and hypothesized that fascin imparts rigidity to forming filopodia to effectively push the membrane forward [25]. A study recently reported that fascin expression of high-intensity was associated with the progression-free survival and overall survival of GBM [2]. Furthermore, a previous study analyzed the effects of fascin manipulations in different glioma cell lines, and reported that fascin depletion in glioma cells led to decreased migration in an ex vivo model and decreased filopodial formation. Therefore, fascin may play a central role in the invasiveness of glioma cells [1].

Curcumin is the key curcuminoid of turmeric, an Indian spice derived from the plant Curcuma longa Linn [9]. Therapeutic effects on different cancers have been recently reported $[9$, $15,26]$. Besides showing a cytotoxicity to cancer cells, it has been demonstrated that curcumin can modulate the radio- and chemosensitivity of cancer cells [12,27-29]. Additionally, the possible benefits of curcumin as a therapeutic treatment for GBM have been investigated in various studies, and diverse mechanisms including initiation of cell cycle arrest and suppression of glioma cells invasion have been demonstrated [13, $14,17,30-32]$.

However, to the best of our knowledge, no study has investigated whether curcumin affects fascin expression in GBM cells. We first hypothesized curcumin may effect fascin expression, and this mechanism may subsequently influence the migration and invasion of GBM cells. Our results demonstrated that curcumin was significantly related with the suppression of fascin expression. And, according to attachment, migration, and invasion assays, curcumin significantly suppressed migration and invasion capacities of GBM cells in spite of a minimally lethal concentration of curcumin and exposure time. Therefore, the present study may suggest that curcumin is related to the anti-migration and anti-invasion mechanisms by suppression of the fascin expression in GBM cells [33].

STAT3 is a well-known transcription factor and regulates a variety of cellular processes, including cell proliferation and 

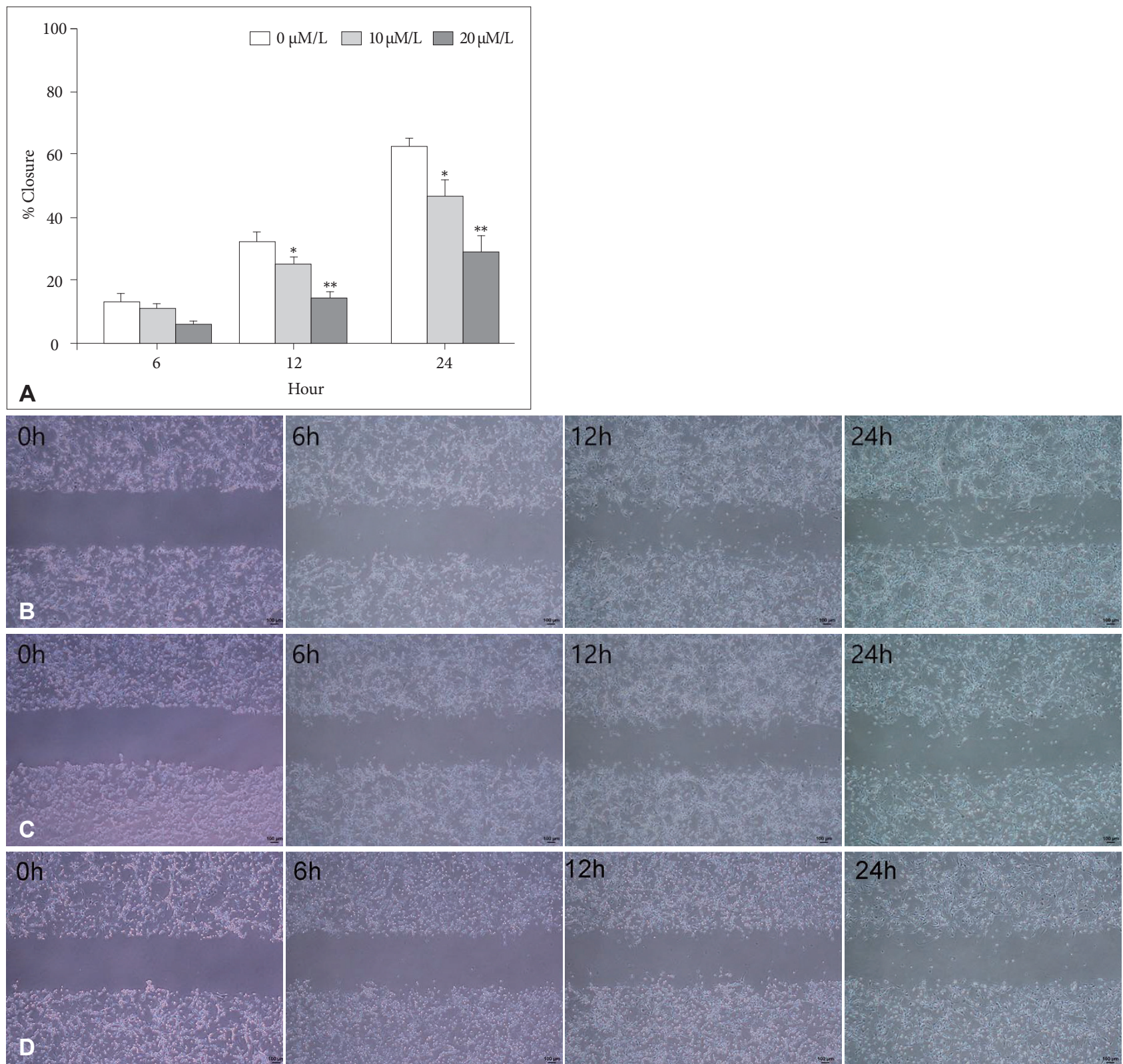

Fig. 4. Migration assay and microscopic images (magnification $\times 100$ ). A: The migration ability of GBM cells showed a statistically significant decline after 6 hours, and the closure percentage of GBM cells showed statistical differences when compared to control (10 $\mu \mathrm{M} / \mathrm{L}$ and 20 $\mu \mathrm{M} / \mathrm{L}$ at 12 hours: $24.2 \%$ and $58.1 \%, p=0.031$ and $p<0.001$; at $10 \mu \mathrm{M} / \mathrm{L}$ and $20 \mu \mathrm{M} / \mathrm{L}$ at 24 hours: $25.0 \%$ and $54.3 \%, p=0.002$ and $p<0.001)$. B: After $0 \mu \mathrm{M} / \mathrm{L}$ curcumin during 6 hours, a photograph showed the migration capacity of GBM cells after $0,6,12$, and 24 hours. C: After $10 \mu \mathrm{M} / \mathrm{L}$ curcumin for 6 hours, a photograph showed the migration capacity of GBM cells after $0,6,12$, and 24 hours. D: After $20 \mu M / L$ curcumin for 6 hours, a photograph showed the migration capacity of GBM cells after $0,6,12$, and 24 hours. Data were presented as the mean \pm SD. ${ }^{*} p<0.05$, ${ }^{* *} p<0.001$ compared to the control group. GBM, glioblastoma.

survival, oncogenesis, and cancer metastasis [5]. Yao et al. [5] demonstrated that STAT3 acts by positively regulating fascin expression, and subsequent augmentation of cell migration and invasion in gastric cancer. Additionally, STAT3 may play a central role in the invasion and migration properties of GBM cells. Senft et al. [34] demonstrated that interference with the JAK/STAT3 pathway affects GBM migration and invasion. And, Parsa [18] suggested that STAT3 was considered recently to be a master regulator of human gliomas, and was there- fore essential to maintaining a tumor's initiating capacity and power to invade brain parenchyma. Our result also demonstrated that the change of phosphrylated STAT3 level by curcumin was consistent with the change of fascin expression by curcumin. And, these findings were connected to a change in migration and invasion capacities. Therefore, the present study may suggest that curcumin can induce the suppression of fascin expression via inhibition of STAT3 phophorylation.

Another finding of our study was that the suppression of 

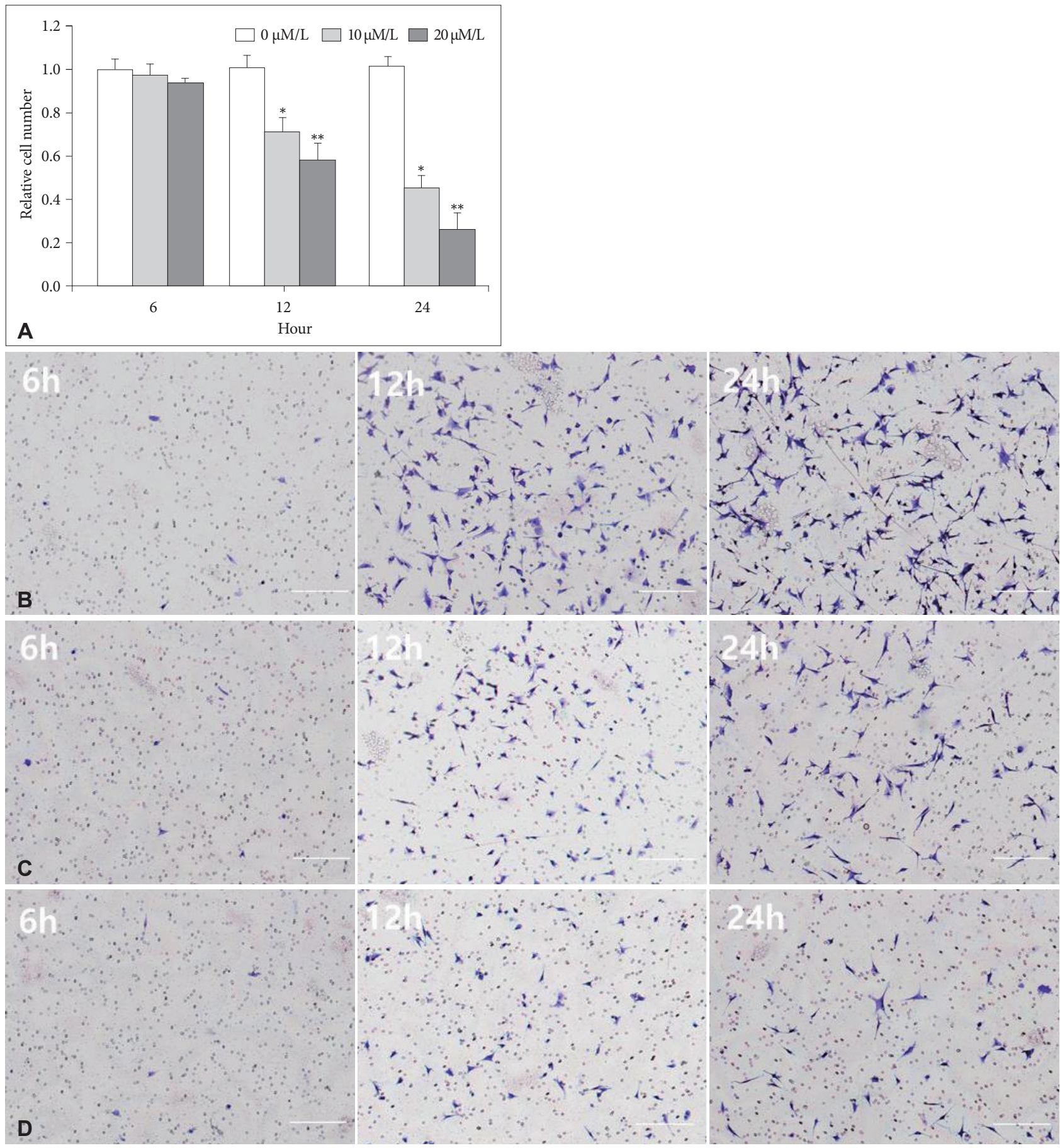

Fig. 5. Invasion assay with microscopic images (magnification $\times 100$ ). A: The invasion ability of GBM cells showed a statistically significant decline after 6 hours $(10 \mu \mathrm{M} / \mathrm{L}$ and $20 \mu \mathrm{M} / \mathrm{L}$ at 12 hours: $28.8 \%$ and $43.2 \%, p=0.046$ and $p<0.001 ; 10 \mu \mathrm{M} / \mathrm{L}$ and $20 \mu \mathrm{M} / \mathrm{L}$ at 24 hours: $54.1 \%$ and $73.8 \%, p=0.001$ and $p<0.001)$. B: After $0 \mu \mathrm{M} / \mathrm{L}$ curcumin for 6 hours, a photograph showed the migration capacity of GBM cells after 6 , 12 , and 24 hours. C: After $10 \mu \mathrm{M} / \mathrm{L}$ curcumin for 6 hours, a photograph showed the migration capacity of GBM cells after 6,12 , and 24 hours. D: After $20 \mu \mathrm{M} / \mathrm{L}$ curcumin for 6 hours, a photograph showed the migration capacity of GBM cells after 6,12 , and 24 hours. Data were presented as the mean \pm SD. ${ }^{*} p<0.05,{ }^{* *} p<0.001$ compared to the control group. GBM, glioblastoma.

fascin expression by curcumin may influence cell shape and filopodia formation. Fascin functions are related to cortical cell protrusions, which mediate cell interaction and migration within an extracelluar matrix, and cytoplasmic microfilamen- tous bundles, which play a role in cell architecture and cellular movement [2,24]. Our result demonstrated that cell shape was modified from a typical spindle form of uninfluenced cells to an appearance that was more polygonal. In addition, a sig- 

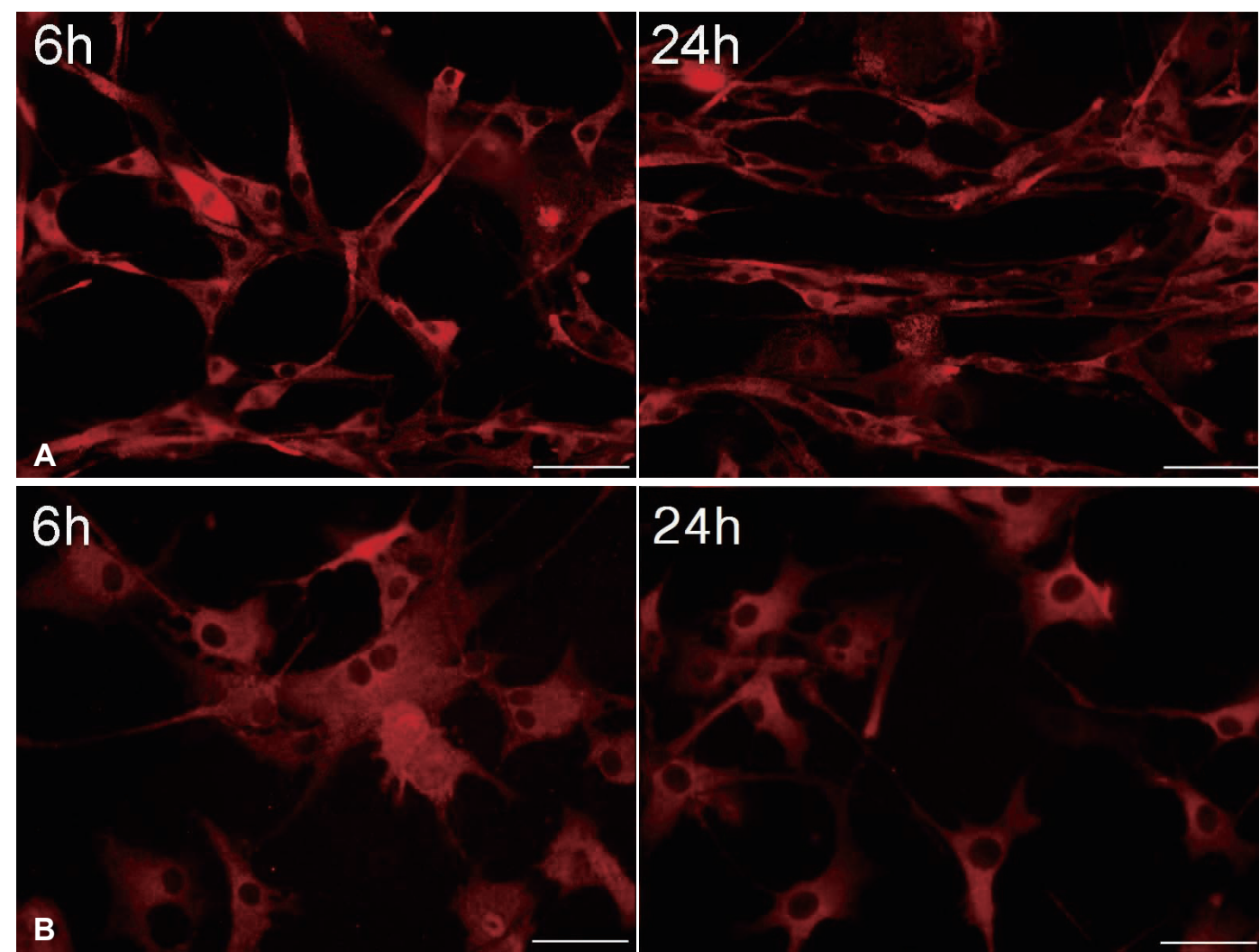

Fig. 6. After temporary exposure to $0 \mu \mathrm{M} / \mathrm{L}(\mathrm{A})$ and $10 \mu \mathrm{M} / \mathrm{L}(\mathrm{B})$ curcumin for 6 hours, immunofluorescence at 6 and 24 hours showed a change in cell shape from a typical spindle form of uninfluenced cells to a more polygonal appearance, and a significant reduction in filopodia formation of glioblastoma cells $(\times 400)$.

nificant reduction in filopodia formation was observed. Even though filopodia remained, the length was shorter compared to controls. These morphological changes did not recover even though fascin expression recovered. These findings might also explain the reason why the migration and invasion capacities continuously decreased even though fascin expression recovered after exposure to a minimally lethal concentration and time.

There are a few limitations in the present study. First, only one GBM cell line was used for the research. The results of statistical analysis cannot be generalized and should be interpreted cautiously. Second, curcumin might partially influence the viability of GBM cells. Although the research was performed under a minimally lethal concentration of curcumin and exposure time, approximately less than 10 percent of cells decreased from the curcumin compared to the control cells. Third, fascin is the final protein and the upstream pathways of fascin expression remain unknown. Therefore, we did not explain the effect of curcumin on upstream molecular pathways related to fascin expression, except STAT expression. Fourth, it is possible that the effect of curcumin could partially influence matrix metalloproteinase (MMP) suppression, because curcumin influenced STAT3, which is also related to MMP expression. The effect of curcumin on MMP could not be ful- ly excluded.

Therefore, in order to have a more definitive mechanism of anti-migration and anti-invasion of curcumin in GBM, additional research to find out more upstream pathways of fascin expression should be considered.

In conclusion, the present study showed that curcumin suppresses fascin expression of GBM cells, which is likely to be influenced by interference with a STAT3 signaling pathway. And, the suppression of fascin expression by curcumin consequently may be related to a decrease in migration and invasion capacities in GBM cells. Therefore, the suppression of fascin expression by curcumin via inhibition of STAT3 phosphorylation should be considered in a possible mechanism for anti-migration and anti-invasion effects of curcumin in GBM cells.

\section{Conflicts of Interest}

The authors have no potential conflicts of interest.

\section{REFERENCES}

1. Hwang JH, Smith CA, Salhia B, et al. The role of fascin in the migration and invasiveness of malignant glioma cells. Neoplasia 2008;10:149-59.

2. Park KS, Lee HW, Park SH, et al. The clinical significance of fascin expression in a newly diagnosed primary glioblastoma. J Neurooncol 2016; 129:495-503.

3. Roma AA, Prayson RA. Fascin expression in 90 patients with glioblas- 
toma multiforme. Ann Diagn Pathol 2005;9:307-11.

4. Al-Alwan M, Olabi S, Ghebeh $\mathrm{H}$, et al. Fascin is a key regulator of breast cancer invasion that acts via the modification of metastasis associated molecules. PLoS One 2011;6:e27339.

5. Yao J, Qian CJ, Ye B, et al. Signal transducer and activator of transcription 3 signaling upregulates fascin via nuclear factor- $\kappa \mathrm{B}$ in gastric cancer: implications in cell invasion and migration. Oncol Lett 2014;7:902-8.

6. Gunal A, Onguru O, Safali M, et al. Fascin expression [corrected] in glial tumors and its prognostic significance in glioblastomas. Neuropathology 2008;28:382-6.

7. Joo JD, Kim H, Kim YH, et al. Validation of the effectiveness and safety of temozolomide during and after radiotherapy for newly diagnosed glioblastomas: 10-year experience of a single institution. J Korean Med Sci 2015;30:1597-603.

8. Peraud A, Mondal S, Hawkins C, et al. Expression of fascin, an actinbundling protein, in astrocytomas of varying grades. Brain Tumor Pathol 2003;20:53-8.

9. Sordillo LA, Sordillo PP, Helson L. Curcumin for the treatment of glioblastoma. Anticancer Res 2015;35:6373-8.

10. Aggarwal BB, Kumar A, Bharti AC. Anticancer potential of curcumin: preclinical and clinical studies. Anticancer Res 2003;23:363-98.

11. López-Lázaro M. Anticancer and carcinogenic properties of curcumin: considerations for its clinical development as a cancer chemopreventive and chemotherapeutic agent. Mol Nutr Food Res 2008;52 Suppl 1:S10327.

12. Hartojo W, Silvers AL, Thomas DG, et al. Curcumin promotes apoptosis, increases chemosensitivity, and inhibits nuclear factor kappaB in esophageal adenocarcinoma. Transl Oncol 2010;3:99-108.

13. Belkaid A, Copland IB, Massillon D, et al. Silencing of the human microsomal glucose-6-phosphate translocase induces glioma cell death: potential new anticancer target for curcumin. FEBS Lett 2006;580:374652.

14. Nagai S, Kurimoto M, Washiyama K, et al. Inhibition of cellular proliferation and induction of apoptosis by curcumin in human malignant astrocytoma cell lines. J Neurooncol 2005;74:105-11.

15. Patel BB, Gupta D, Elliott AA, et al. Curcumin targets FOLFOX-surviving colon cancer cells via inhibition of EGFRs and IGF-1R. Anticancer Res 2010;30:319-25.

16. Senft C, Polacin M, Priester M, et al. The nontoxic natural compound Curcumin exerts anti-proliferative, anti-migratory, and anti-invasive properties against malignant gliomas. BMC Cancer 2010;10:491.

17. Woo MS, Jung SH, Kim SY, et al. Curcumin suppresses phorbol esterinduced matrix metalloproteinase- 9 expression by inhibiting the PKC to MAPK signaling pathways in human astroglioma cells. Biochem Biophys Res Commun 2005;335:1017-25.

18. Parsa AT. A newly identified transcriptional network for mesenchymal transformation of brain tumors: potential targets for therapeutic intervention. World Neurosurg 2010;73:424.
19. Adams JC. Formation of stable microspikes containing actin and the 55 $\mathrm{kDa}$ actin bundling protein, fascin, is a consequence of cell adhesion to thrombospondin-1: implications for the anti-adhesive activities of thrombospondin-1. J Cell Sci 1995;108 (Pt 5):1977-90.

20. Adams JC. Characterization of cell-matrix adhesion requirements for the formation of fascin microspikes. Mol Biol Cell 1997;8:2345-63.

21. Adams JC, Kureishy N, Taylor AL. A role for syndecan-1 in coupling fascin spike formation by thrombospondin-1. J Cell Biol 2001;152:1169-82.

22. Edwards RA, Bryan J. Fascins, a family of actin bundling proteins. Cell Motil Cytoskeleton 1995;32:1-9.

23. Edwards RA, Herrera-Sosa H, Otto J, et al. Cloning and expression of a murine fascin homolog from mouse brain. J Biol Chem 1995;270:1076470 .

24. Kureishy N, Sapountzi V, Prag S, et al. Fascins, and their roles in cell structure and function. Bioessays 2002;24:350-61.

25. Vignjevic D, Kojima S, Aratyn Y, et al. Role of fascin in filopodial protrusion. J Cell Biol 2006;174:863-75.

26. Kunnumakkara AB, Anand P, Aggarwal BB. Curcumin inhibits proliferation, invasion, angiogenesis and metastasis of different cancers through interaction with multiple cell signaling proteins. Cancer Lett 2008;269:199-225.

27. Dhandapani KM, Mahesh VB, Brann DW. Curcumin suppresses growth and chemoresistance of human glioblastoma cells via AP-1 and NFkappaB transcription factors. J Neurochem 2007;102:522-38.

28. Kunnumakkara AB, Diagaradjane P, Anand P, et al. Curcumin sensitizes human colorectal cancer to capecitabine by modulation of cyclin D1, COX-2, MMP-9, VEGF and CXCR4 expression in an orthotopic mouse model. Int J Cancer 2009;125:2187-97.

29. Sandur SK, Deorukhkar A, Pandey MK, et al. Curcumin modulates the radiosensitivity of colorectal cancer cells by suppressing constitutive and inducible NF-kappaB activity. Int J Radiat Oncol Biol Phys 2009; 75:534-42.

30. Gao X, Deeb D, Jiang H, et al. Curcumin differentially sensitizes malignant glioma cells to TRAIL/Apo2L-mediated apoptosis through activation of procaspases and release of cytochrome $\mathrm{c}$ from mitochondria. J Exp Ther Oncol 2005;5:39-48.

31. Karmakar S, Banik NL, Patel SJ, et al. Curcumin activated both receptor-mediated and mitochondria-mediated proteolytic pathways for apoptosis in human glioblastoma T98G cells. Neurosci Lett 2006;407: 53-8.

32. Kim SY, Jung SH, Kim HS. Curcumin is a potent broad spectrum inhibitor of matrix metalloproteinase gene expression in human astroglioma cells. Biochem Biophys Res Commun 2005;337:510-6.

33. Liu C, Gao H, Cao L, et al. The role of FSCN1 in migration and invasion of pituitary adenomas. Mol Cell Endocrinol 2016;5;419:217-24.

34. Senft C, Priester M, Polacin M, et al. Inhibition of the JAK-2/STAT3 signaling pathway impedes the migratory and invasive potential of human glioblastoma cells. J Neurooncol 2011;101:393-403. 